\title{
Mechanical and Damping Properties of Fullerene-Dispersed AZ91 Magnesium Alloy Composites Processed by a Powder Metallurgy Route
}

\author{
Hiroyuki Watanabe ${ }^{1}$, Masami Sugioka ${ }^{1}$, Masao Fukusumi ${ }^{1}$, Koichi Ishikawa ${ }^{1, *}$, \\ Mitsuo Suzuki ${ }^{2}$ and Toru Shimizu ${ }^{3}$ \\ ${ }^{1}$ Osaka Municipal Technical Research Institute, Osaka 536-8553, Japan \\ ${ }^{2}$ Research \& Development Center, Frontier Carbon Corporation, Yokohama 227-0033, Japan \\ ${ }^{3}$ Osaka Branch Office, Mitsubishi Chemical Corporation, Osaka 541-0044, Japan
}

\begin{abstract}
The microstructures and mechanical properties of fullerene powder dispersed AZ91 magnesium alloy composites were examined. The AZ91 with 0, 1 and 5 mass \% fullerene additions were produced by extruding a mixture of AZ91 machined chips and fullerene powder. The matrix grains of the extruded materials were equiaxed, and the size was $\sim 5 \mu \mathrm{m}$ irrespective of the fullerene content. The agglomerated fullerene powder was aligned parallel to the extrusion direction in the composites. The addition of 1 mass $\%$ fullerene had little effect on the elastic moduli, tensile strength and ductility, whereas the addition of 5 mass $\%$ fullerene slightly decreased them. A comparison between the tensile properties of the present composites and those of AZ91 alloys processed by various methods was also made. The damping capacity increased steeply by the fullerene addition. The effectiveness of the fullerene addition for the enhancement of the damping capacity of metallic alloys was verified. A good combination of damping capacity, elastic moduli, strength and ductility was attained in the present composites.
\end{abstract}

(Received October 7, 2005; Accepted February 15, 2006; Published April 15, 2006)

Keywords: magnesium alloy, fullerene, magnesium-matrix-composite, powder metallurgy, elastic properties, tensile properties, damping

\section{Introduction}

Recently, there has been a significant increase in the use of magnesium as a structural material because of the lightness of magnesium alloys. In addition, pure magnesium and some magnesium alloys are well known as damping materials. ${ }^{1-3)}$ Therefore, magnesium alloys are very attractive in applications for the automotive, railway and aerospace industries. AZ91 alloy is the most widely used cast magnesium alloy. This is because this alloy shows a good combination of high strength at room temperature, good castability and excellent corrosion resistance. However, the damping capacity of typical Mg-Al system alloys-for example, AZ91 and AZ31-is not that high compared with that of pure magnesium. ${ }^{4)}$ Light-weight magnesium-based materials with a high damping capacity need to be developed in order to control vibration and noise in vehicles and instruments. The metal-matrix-composite technology provides an approach to combining a high damping reinforcement into a low damping matrix to produce a high damping material. For example, graphite, carbon fiber, carbon powder and $\mathrm{Al}_{2} \mathrm{O}_{3}$ fiber have been examined as reinforcements for the purpose of enhancing the resultant damping of magnesium-based composites. ${ }^{5-9)}$ However, the effect of the reinforcement addition is either small when the volume fraction, $V_{\mathrm{f}}$, is moderate $\left(V_{\mathrm{f}}=10-25 \%\right)^{7-9)}$ or high only when the volume fraction is extremely high $\left.\left(V_{\mathrm{f}} \sim 40 \%\right) .{ }^{6}\right)$

Since the discovery of fullerenes and carbon nanotubes (CNTs), a great deal of attention has been given to their characterization and potential applications. To date, diverse new materials comprising superconductors, fuel cell, and catalysts have been developed for these carbon materials. In structural materials, due to a nano-sized dispersion of fullerenes and CNTs, metallic alloys reinforced with these

*Present address: Shimaya Business Incubator, Osaka 554-0024, Japan carbon materials are expected to offer attractive properties such as higher strength and damping capacity. ${ }^{10)}$ Though an increase in strength has been observed in fullerene- or CNTdispersed aluminum-matrix-composites, ${ }^{11-16)}$ their performance has not often been as good as had been expected. Moreover, the addition of these carbon materials generally drastically decreases the ductility of the composites. However, although the effectiveness of fullerene addition to the damping behavior of metallic alloys has not been verified, it is highly expected that a fullerene-dispersed magnesiummatrix-composite possesses high damping capacity.

In our preliminary experiments, it was difficult to disperse fullerene powder in the liquid magnesium despite stirring; the fullerene powder was separated from the liquid. Therefore, in the present study, AZ91 magnesium alloy with 0,1 and 5 mass $\%$ fullerene additions were processed by the powder metallurgy route. Microstructures and mechanical properties, including the elastic moduli, strength, elongation and damping capacity of the processed materials were examined.

\section{Experimental}

\subsection{Materials}

The material used in the present study was a commercial AZ91 magnesium alloy. The powder metallurgy route was used to produce magnesium alloy composites with 1 and 5 mass $\%$ fullerene additions (hereafter, denoted as AZ91/ $\mathrm{C}_{60}-1 \%$ and $\mathrm{AZ} 91 / \mathrm{C}_{60}-5 \%$, respectively). The procedure used to prepare the composite is schematically shown in Fig. 1. Fullerene powder (Nanom Mix MF-S), a mixture of $60 \% \mathrm{C}_{60}, 25 \% \mathrm{C}_{70}$ and a balance of higher order fullerenes, was obtained from Frontier Carbon Corp., Japan. The fullerene powder is thermally stable below $\sim 573 \mathrm{~K}$ in air. The AZ91 powder was prepared by machining an ingot in a lathe in air. Before machining, the ingot was solution-treated at $686 \mathrm{~K}$ for $48 \mathrm{~h}$. The machined chips were mixed with 


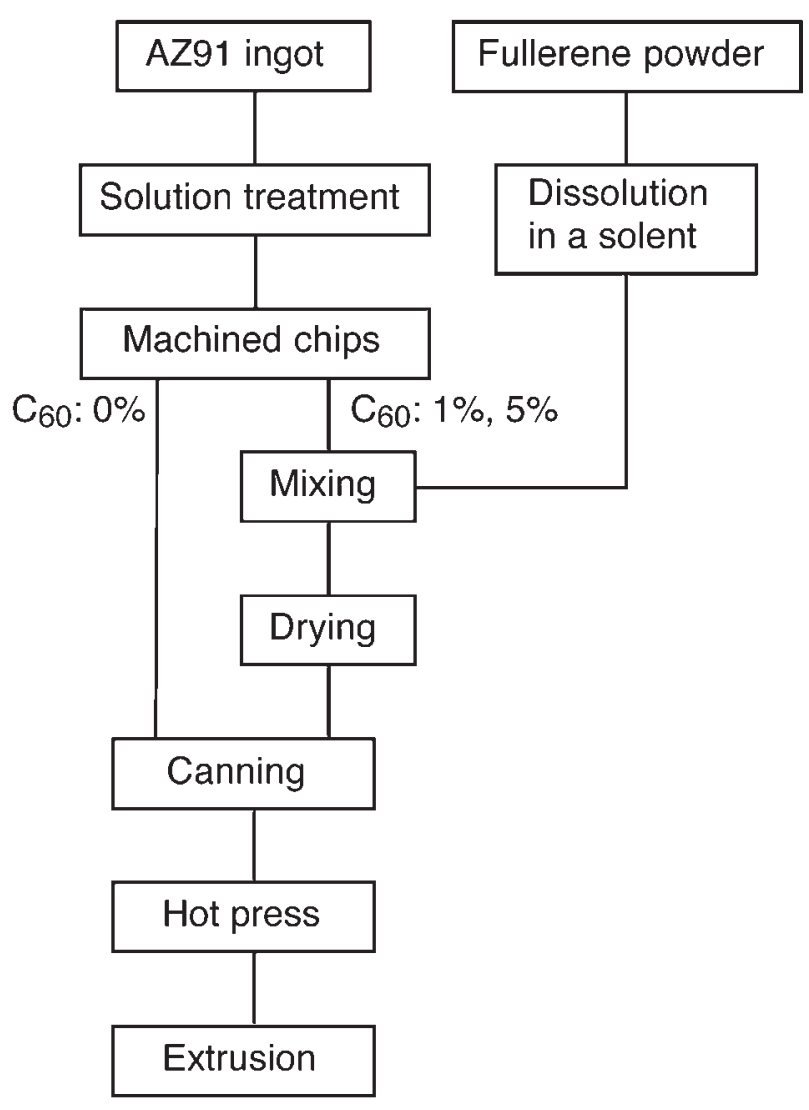

Fig. 1 Flow chart illustrating the method used to produce $A Z 91 / \mathrm{C}_{60}-0 \%$, $\mathrm{AZ} 91 / \mathrm{C}_{60}-1 \%$ and $\mathrm{AZ} 91 / \mathrm{C}_{60}-5 \%$.

fullerene-dissolved toluene. The ratio of fullerene to toluene was $2.9 \mathrm{~g} / \mathrm{L}$, which is the solubility of $\mathrm{C}_{60}$ in a toluene at room temperature. ${ }^{17)}$ This process was intended to disperse the fullerene powder onto the machined chips as uniformly as possible. The drying of the mixture was completed by the volatilization of toluene. The mixtures were tap-packed into a capsule made of AZ31 magnesium alloy having an outer diameter of $40 \mathrm{~mm}$ in air. The mixed powder was pressed at a temperature of $473 \mathrm{~K}$ under an applied pressure of $\sim 3 \mathrm{MPa}$ in air for the densification. The billets were then extruded at $573 \mathrm{~K}$ with a reduction ratio of 16 . For reference, AZ91 alloy without fullerene addition (hereafter, denoted as $\mathrm{AZ91/ \textrm {C } _ { 6 0 }}$ $0 \%$ ) was also produced by a similar method.

\subsection{Microstructural observations}

Optical microstructures were observed by a color laser 3D profile microscope using a light screen mode. Scanning electron microscopes (SEMs) were used in the secondary electron (SE) mode and the backscattered electron (BE) mode. Wavelength-dispersive spectroscopy (WDS) was also used in the SEM to chemically analyze the microstructural elements.

The phase identification was performed by X-ray diffractometry (XRD) for fullerene powder, machined chips and extruded $\mathrm{AZ91} / \mathrm{C}_{60}-1 \%$. The XRD scans were made using $\mathrm{Cu} K_{\alpha} \mathrm{X}$-rays by a parallel beam method.

\subsection{Mechanical testing}

The tensile specimens machined from the extruded bars had tensile axes parallel to the extrusion direction. The specimens had a parallel length of $20 \mathrm{~mm}$ and a diameter of $4 \mathrm{~mm}$. Tensile tests were carried out at room temperature and at an initial strain rate of $5 \times 10^{-4} \mathrm{~s}^{-1}$. The strain up to $9 \%$ was measured by an extensometer with a gauge length of $12.5 \mathrm{~mm}$. The yield strength (YS) $(0.2 \%$ proof strength), ultimate tensile strength (UTS) and elongation-to-failure $\left(e_{\mathrm{f}}\right)$ were calculated.

The elastic properties were measured by employing the method of resonant vibration; ${ }^{18)}$ Young's modulus and the shear modulus were determined from the resonant frequency in the flexural and torsional modes of vibration, respectively, by the following equations:

$$
\begin{aligned}
E & =9.4645 \times 10^{-13}\left(\frac{l}{h}\right)^{3}\left(\frac{m}{w}\right) f^{2} K_{1} \\
G & =4 \times 10^{-12}\left(\frac{l m}{h w}\right)\left(\frac{1}{K}\right) f^{2} \frac{1}{K_{2}}
\end{aligned}
$$

where $E[\mathrm{GPa}]$ is the Young's modulus, $G[\mathrm{GPa}]$ is the shear modulus, $l, h$ and $w[\mathrm{~m}]$ are the length, thickness and width for the rectangular specimen, respectively, $m[\mathrm{~g}]$ is the mass of the specimen, $f[\mathrm{~Hz}]$ is the resonant frequency for the fundamental, $K_{1}$ and $K_{2}$ are the correction factors of approximately unity, ${ }^{18)}$ and $K$ is a constant approximated as ${ }^{19)}$

$$
K=\frac{4(h / w)-2.52(h / w)^{2}+0.21(h / w)^{6}}{\left(h^{2}+w^{2}\right) / h w}
$$

The specimens for the measurement of the elastic moduli had a rectangular shape with a length of $60 \mathrm{~mm}$, width of $7.5 \mathrm{~mm}$ and thickness of $1.8 \mathrm{~mm}$. The specimens were prepared by machining. The longitudinal direction was parallel to the extrusion direction.

The specimens for measuring the damping properties had a diameter of $6 \mathrm{~mm}$ with a flat portion of the length $62 \mathrm{~mm}$ and a width of $3.6 \mathrm{~mm}$, as shown in Fig. 2. The longitudinal direction was parallel to the extrusion direction. As schematically shown in Fig. 2(b), the end of the test piece was clamped while the other end was free. The maximum surface strain, $\varepsilon$, was measured by a strain gauge. The damping constant was specified by the loss factor, $\eta$, of free vibration, which is related to the logarithmic decrement, $\Lambda$, and calculated by

$$
\eta=\frac{\Lambda}{\pi}=\frac{\ln \left(A_{i} / A_{i+n}\right) / n}{\pi}
$$

where $A_{i}$ and $A_{i+n}$ are the strain amplitudes of the $i$ th cycle and $(i+n)$ th cycle at times $t_{1}$ and $t_{2}$, respectively, separated by $n$ periods of oscillation. The $n$-value was 20 for the present study, as will be shown in Fig. 10.

\section{Results}

\subsection{Microstructures}

Scanning electron micrographs of machined chips mixed with 1 mass \% fullerene are shown in Fig. 3. The appearance of the machined chips is shown in Fig. 3(a). The size of the chips was approximately $500 \mu \mathrm{m}$. The SE images with higher magnifications are shown in Figs. 3(b) and (c), and the dot map of carbon in the same area with Fig. 3(c) is shown in 
(a)

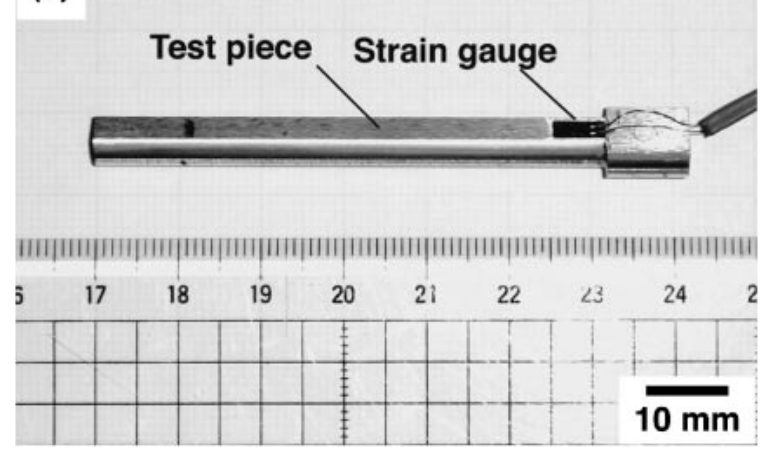

(b)

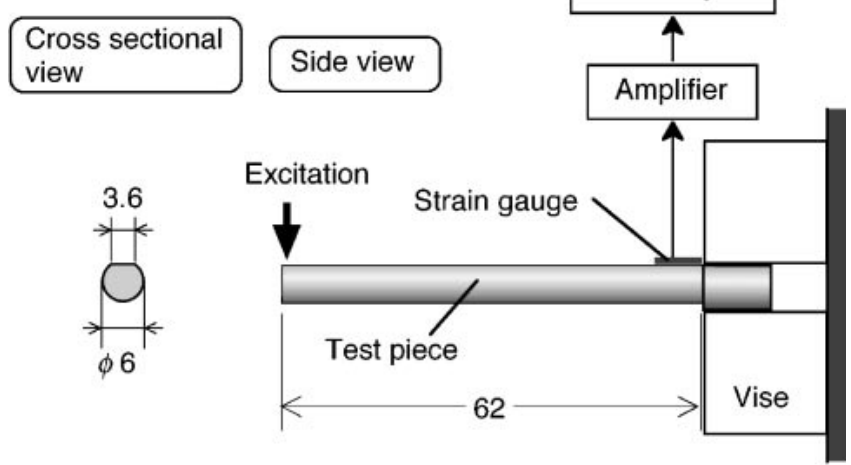

Fig. 2 (a) Appearance of test piece for damping measurement and (b) schematic diagram of the damping measurement.

Fig. 3(d). The light-colored portions on the dot map indicate the presence of carbon. Since the AZ91 alloy basically does not contain carbon, ${ }^{20)}$ the detected carbon corresponds to the fullerene. By comparing Figs. 3(c) and (d), it is apparent that the fullerene existed on the chip surface granularly. The coverage was not uniform, as is evident from Figs. 3(b) and (c): parts of the chip surfaces were exposed even in the densely dispersed area, as indicated by the arrows in Fig. 3(b). It is supposed that the machined chips physically adsorbs the fullerene powder.

The BE images of extruded materials for (a) $A Z 91 / \mathrm{C}_{60}-$ $0 \%$, (b) $\mathrm{AZ} 91 / \mathrm{C}_{60}-1 \%$ and (c) $\mathrm{AZ91} / \mathrm{C}_{60}-5 \%$ are shown in Fig. 4. The extrusion directions are horizontal. There were no voids or cracks for all materials. The material contrast was assumed to basically arise between magnesium matrix (bright) and fullerene (dark). The scanning electron micrographs of extruded AZ91/ $\mathrm{C}_{60}-1 \%$ for (a) SE image and (b) the dot map of carbon in (a) by WDS are shown in Fig. 5. Again, the light-colored portions on the dot map indicate the presence of carbon. Though the dark portions in Fig. 4(a) (e.g., the portion indicated by the arrow) probably correspond to the oxygen resulting from the oxidation of the chip surface, it is confirmed from Fig. 5 that the dark portions in Figs. 4(b) and (c) definitely correspond to the presence of carbon. It is obvious from Fig. 4 that the fullerene phase in the extruded materials assumed a preferred orientation; the agglomerated fullerene powder was aligned parallel to the extrusion direction. This form of dispersion may result from the inability of fullerene agglomerates to infiltrate into the machined chips during solid state processing. It is expected
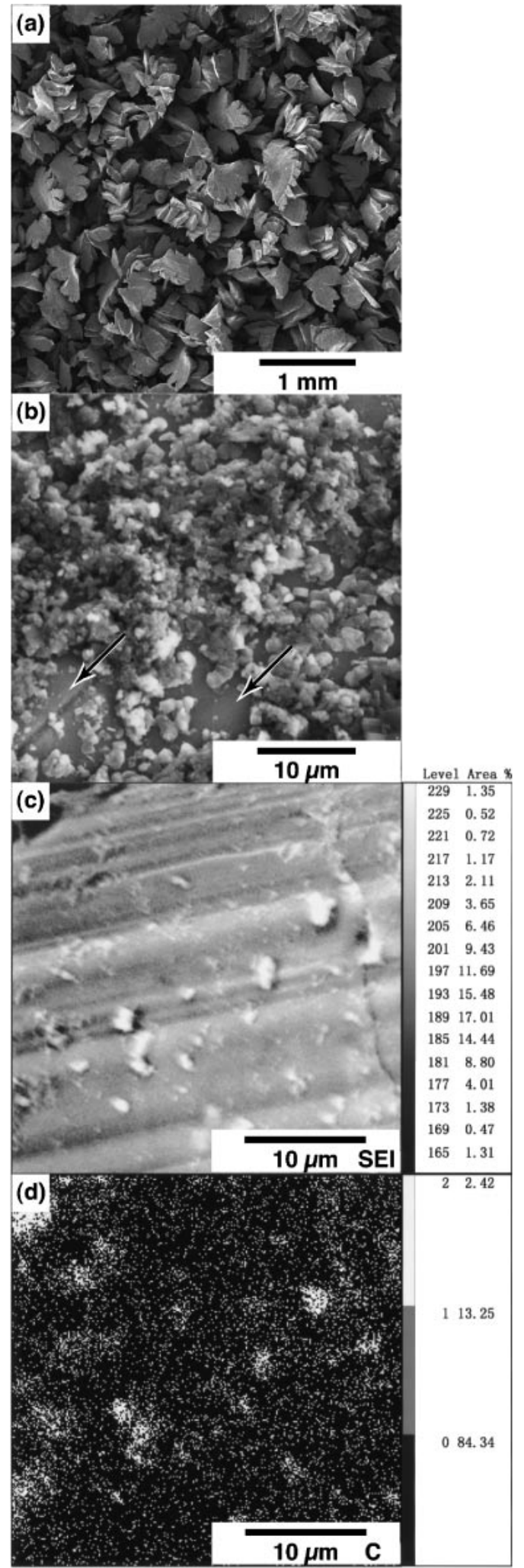

Fig. 3 Scanning electron micrographs of machined chips before canning for (a) SE image with low magnification, (b) SE image with high magnification in the area where fullerene is densely dispersed, (c) SE image with high magnification in the area where fullerene is sparsely dispersed, and (d) dot map of carbon in (c). The mass percent of fullerene is $1 \%$.

that the use of smaller magnesium powder will lead to more homogeneous fullerene dispersion.

XRD profiles of (a) fullerene powder, (b) machined chips 

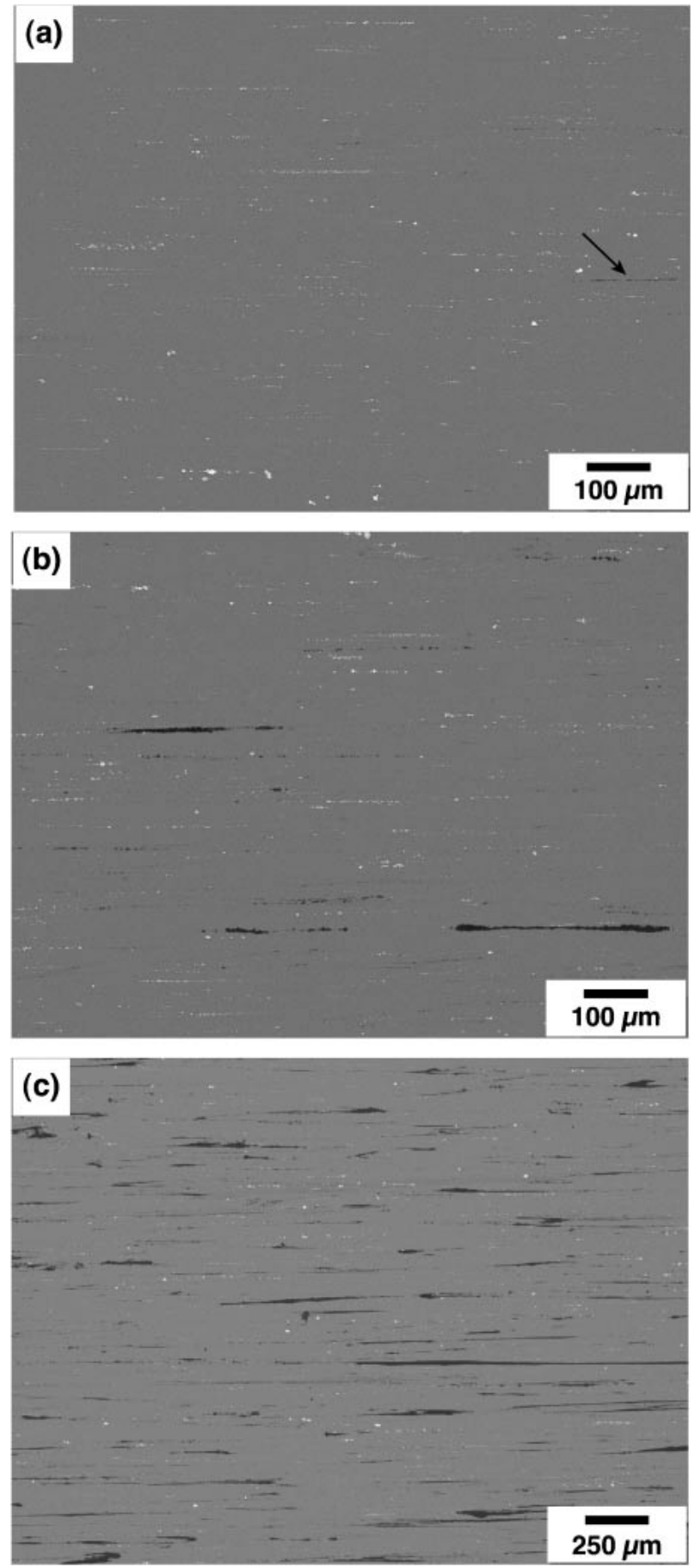

Fig. 4 BE images of extruded materials for (a) AZ91/ $\mathrm{C}_{60}-0 \%$, (b) AZ91/ $\mathrm{C}_{60}-1 \%$ and (c) $\mathrm{AZ} 91 / \mathrm{C}_{60}-5 \%$. The material contrast between magnesium matrix (bright) and fullerene (dark) is pronounced. The extrusion directions are horizontal.

and (c) as-extruded $A Z 91 / \mathrm{C}_{60}-1 \%$ are shown in Fig. 6. For fullerene powder, the peaks were identified with $\mathrm{C}_{60}$ molecules. In machined chips, the peaks were identified with those from solid solution magnesium. After extrusion, the peaks were identified with magnesium and $\mathrm{Mg}_{17} \mathrm{Al}_{12}$. The latter phase probably precipitated dynamically during extrusion as well as cast-extruded AZ91.21) Specific peaks for $\mathrm{C}_{60}$ molecules were not observed in the extruded $\mathrm{AZ} 91 / \mathrm{C}_{60^{-}}$ $1 \%$. This is probably because not enough phase is present to produce diffraction peaks in the composite.

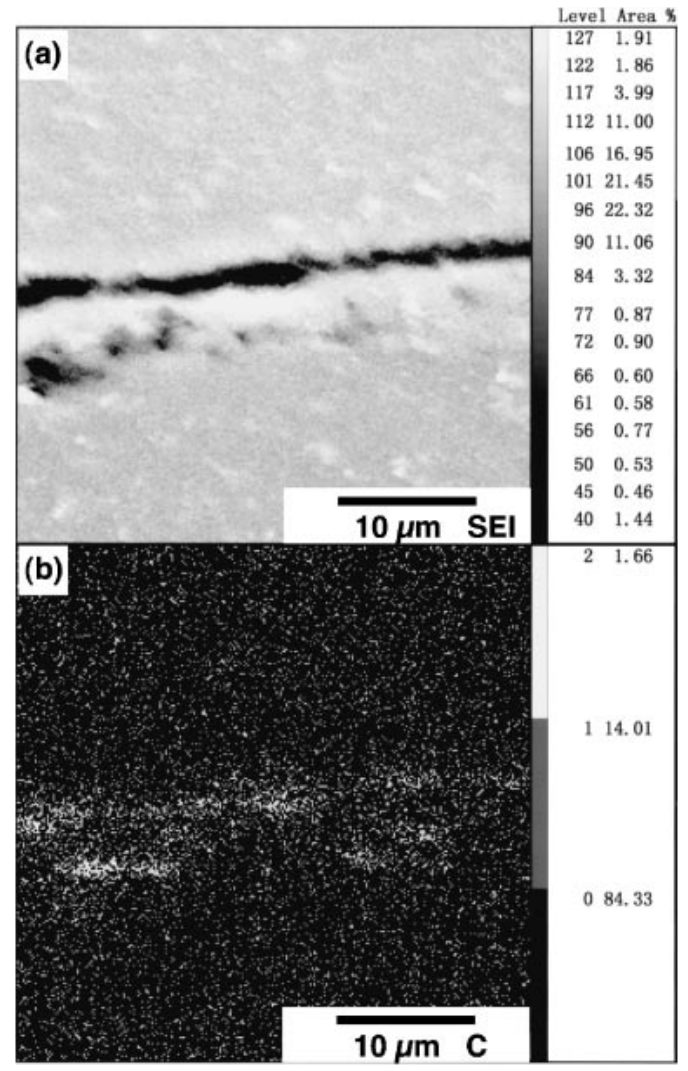

Fig. 5 Scanning electron micrographs of extruded $A Z 91 / \mathrm{C}_{60}-1 \%$ for (a) SE image, and (b) dot map of carbon in (a).

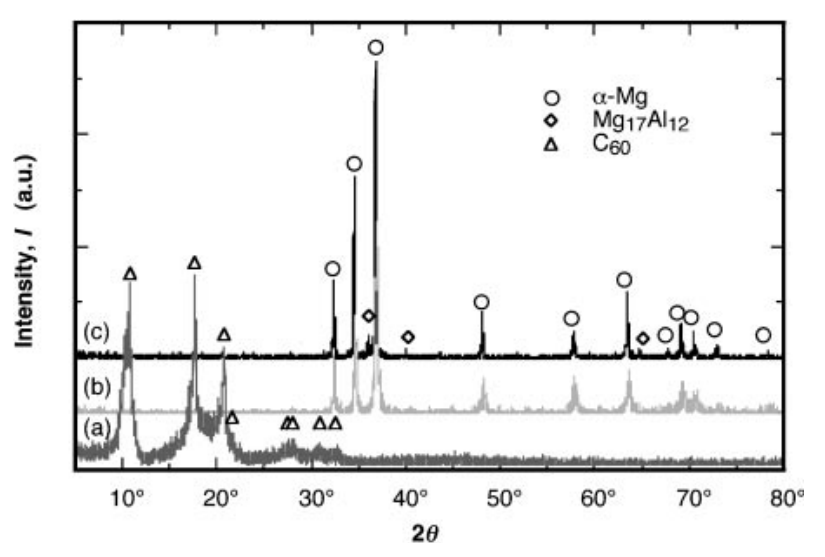

Fig. 6 XRD profiles of (a) fullerene powder, (b) machined chips and (c) extruded $\mathrm{AZ} 91 / \mathrm{C}_{60}-1 \%$

The optical microstructures of extruded materials are shown in Fig. 7 for (a) AZ91/ $\mathrm{C}_{60}-0 \%$, (b) AZ91/ $\mathrm{C}_{60}-1 \%$ and (c) $A Z 91 / C_{60}-5 \%$. All materials had similar grain sizes of $5 \mu \mathrm{m}$, irrespective of fullerene content. Significant grain refinement was observed after extrusion when compared with AZ91 alloy after solid solution treatment, whose grain size is $70-300 \mu \mathrm{m} .{ }^{22)}$ The grain refinement is probably attributed to the dynamic recrystallization during hot extrusion. Spherical particles with a diameter of approximately $0.3 \mu \mathrm{m}$ were observed mainly in the grain boundaries for all materials. This phase is assumed to be $\mathrm{Mg}_{17} \mathrm{Al}_{12}$ from the XRD profile of the AZ91/ $\mathrm{C}_{60}-1 \%$ (Fig. 7(c)). The observed microstruc- 

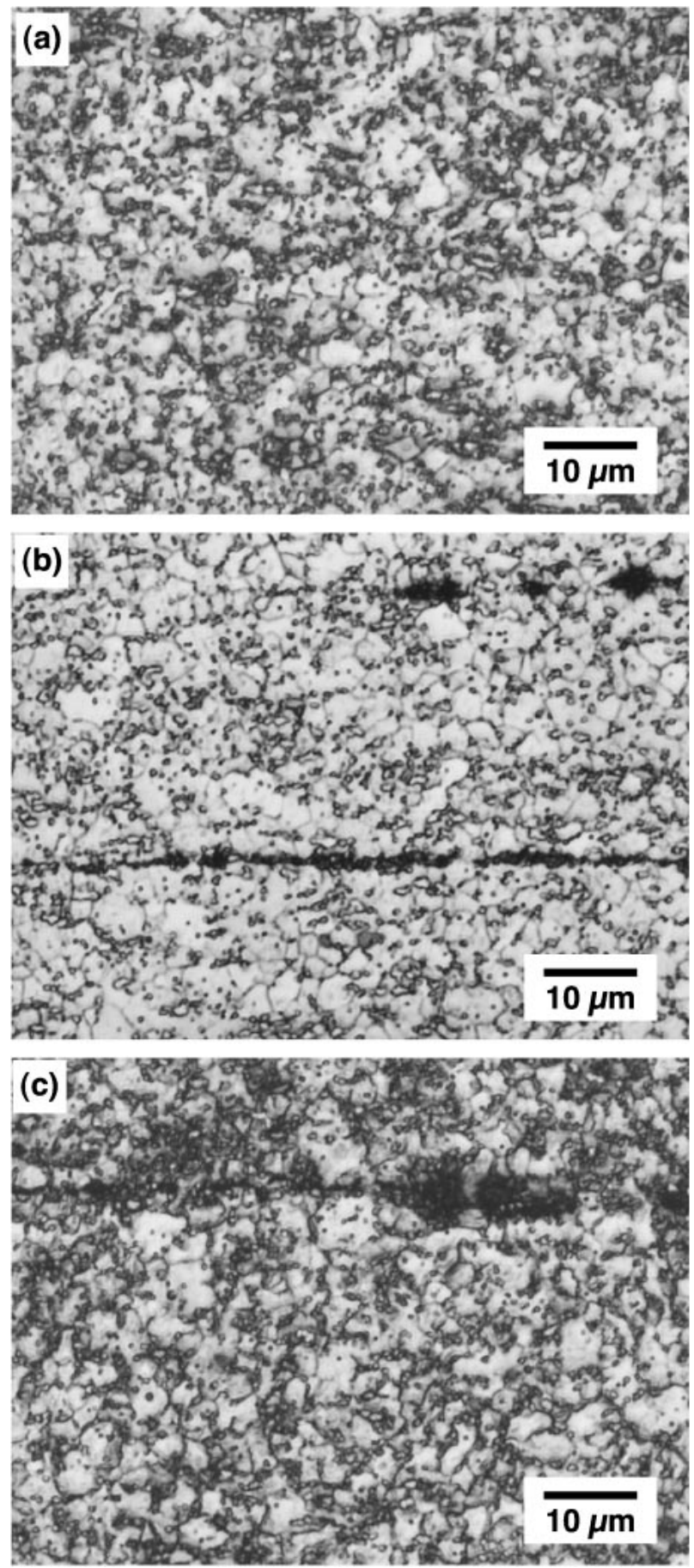

Fig. 7 Optical microstructures of extruded materials for (a) $\mathrm{AZ} 91 / \mathrm{C}_{60}-0 \%$, (b) $\mathrm{AZ} 91 / \mathrm{C}_{60}-1 \%$ and (c) $\mathrm{AZ} 91 / \mathrm{C}_{60}-5 \%$. The extrusion directions are horizontal.

tures suggest that the small addition of fullerene does not affect the resulting microstructure of the matrix.

\subsection{Elastic properties}

Young's modulus and shear modulus for the present materials and some magnesium-based materials ${ }^{20,23-25)}$ are summarized in Table 1. The AZ91/ $\mathrm{C}_{60}-0 \%$ had similar elastic properties with cast AZ91. ${ }^{20)} \mathrm{A}$ small amount of fullerene addition (1 mass $\%$ fullerene) did not change the elastic moduli, but further addition ( 5 mass $\%$ fullerene)
Table 1 Elastic properties of magnesium-based materials.

\begin{tabular}{lccc}
\hline \multicolumn{1}{c}{ Material } & $E / \mathrm{GPa}$ & $G / \mathrm{GPa}$ & Ref. \\
\hline $\mathrm{AZ91} / \mathrm{C}_{60}-0 \%$ & 44.2 & 16.8 & This work \\
$\mathrm{AZ} 91 / \mathrm{C}_{60}-1 \%$ & 44.0 & 16.8 & This work \\
$\mathrm{AZ91} / \mathrm{C}_{60}-5 \%$ & 42.7 & 16.1 & This work \\
$\mathrm{AZ91}$ & 45 & 17 & $20)$ \\
$\mathrm{AZ91} / \mathrm{SiC} / 2 \mathrm{p}$ & 45 & - & $23)$ \\
$\mathrm{Mg}-6 \mathrm{Zn} / \mathrm{SiC} / 20 \mathrm{p}-\mathrm{T} 4$ & 73 & - & $24)$ \\
$\mathrm{Mg} / \mathrm{Al}_{2} \mathrm{O}_{3} / 35 \mathrm{f}$ & 157 & - & $25)$ \\
\hline
\end{tabular}

\begin{tabular}{|c|c|c|}
\hline$\stackrel{0}{+}$ & $\begin{array}{l}\text { AZ91/C } 60^{-0} \% \text { [This work] } \\
\text { AZ91/C } 60^{-1} \% \text { (This work] } \\
\text { AZ91/C } 60^{-5} \% \text { [This work] }\end{array}$ & $\begin{array}{l}\text { - }- \text { Chip+Extr. }[33,34] \\
\diamond \quad \text { RS+Extr. }[37-39] \\
\times \quad \text { Composite }[23-25,40]\end{array}$ \\
\hline$\stackrel{\Delta}{\Delta}$ & $\begin{array}{l}\text { Cast }[20,32-35] \\
\text { - Cast+Extr. }[33,34,36-39] \\
\text { Cast+ECAE [36] }\end{array}$ & \\
\hline
\end{tabular}
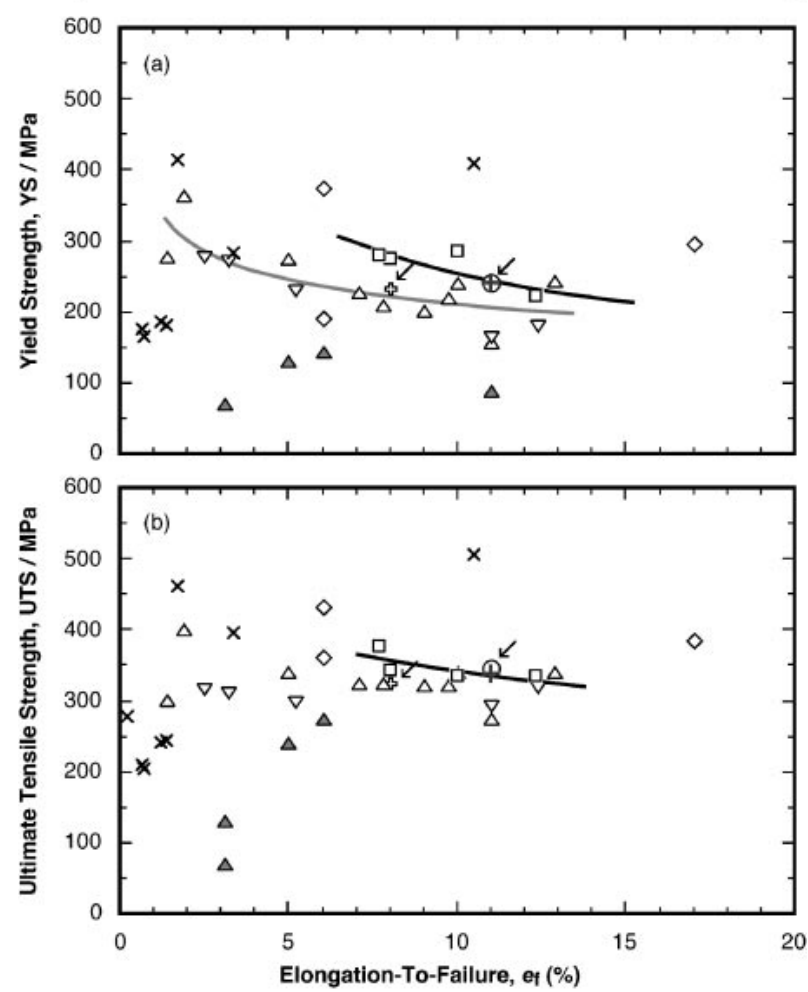

Fig. 8 The relationship between strength ((a) yield strength and (b) ultimate tensile strength) and elongation-to-failure at room temperature for the present materials, AZ91 alloys processed by various techniques ${ }^{20,32-39)}$ and magnesium-based composites. ${ }^{23-25,40)}$

slightly decreased them. This is in contrast to the conventional magnesium-based composites. Though the small amount of $\mathrm{SiC}$ particles did not increase the Young's modulus in the AZ91/SiC composite, ${ }^{23)}$ a remarkable increase has generally been attained in magnesium alloys reinforced with a large amount of ceramic particles or fiber $\left(V_{\mathrm{f}} \geq 20 \%\right){ }^{24,25)}$ as listed in Table 1 . The origin of the slight decrease in elastic moduli for the present composites is assumed to be resulting from low elastic moduli of the fullerene phase in the present composites. Though the bulk modulus of a single $\mathrm{C}_{60}$ molecule is predicted to reach the value of $717 \mathrm{GPa},{ }^{26)}$ this superior stiffness of individual fullerenes is not reflected in the elastic properties of molecular crystals formed of fullerenes. ${ }^{27-31)}$ 

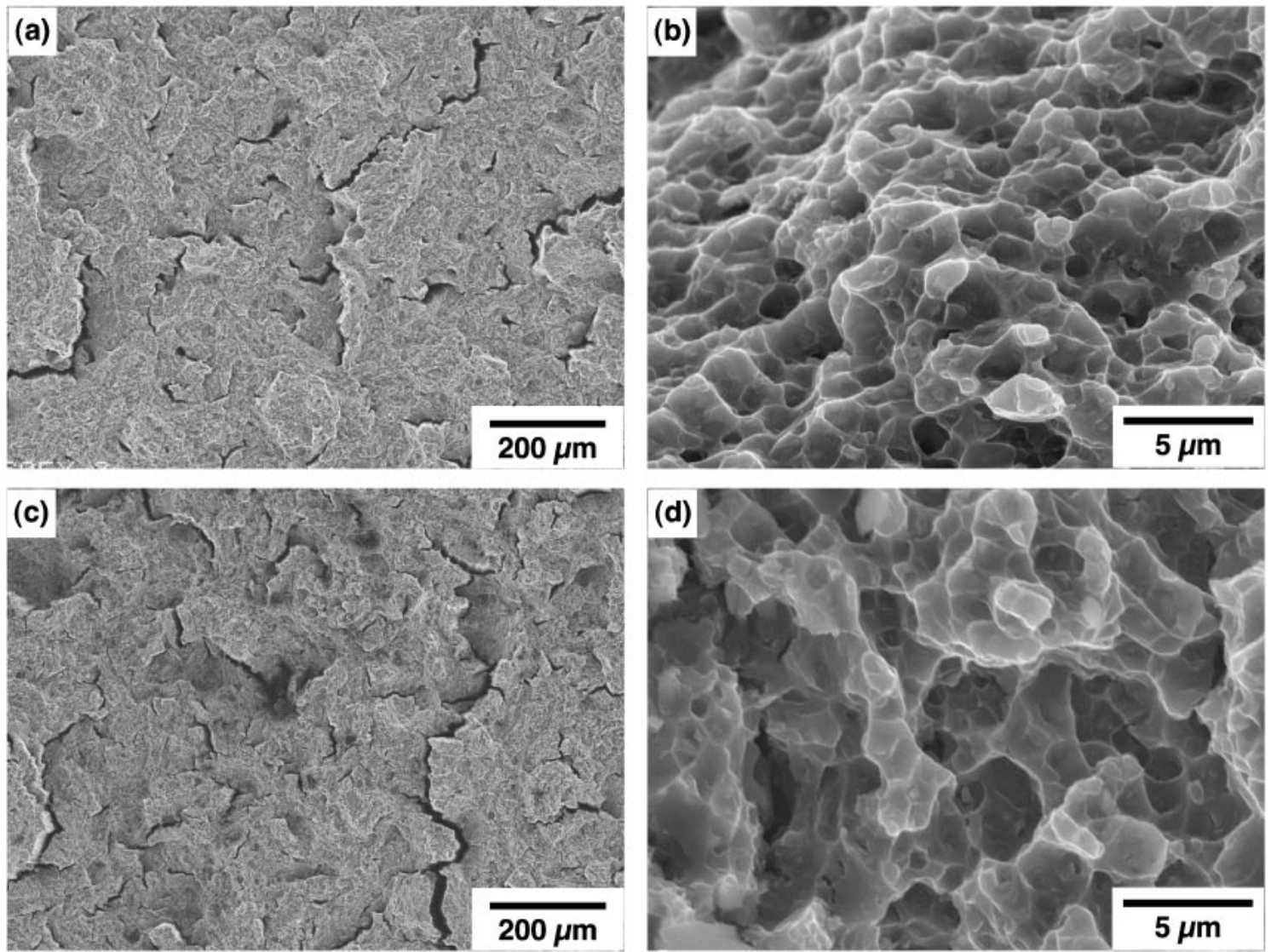

Fig. 9 Fracture surfaces of (a) AZ91/ $\mathrm{C}_{60}-0 \%$ with low magnification (b) AZ91/ $\mathrm{C}_{60}-0 \%$ with high magnification, (c) AZ91/ $\mathrm{C}_{60}-1 \%$ with low magnification and (d) AZ91/ $\mathrm{C}_{60}-1 \%$ with high magnification.

\subsection{Tensile properties}

Yield strength, ultimate tensile strength, elongation-tofailure for the present materials (indicated by the arrows), AZ91 alloys processed by various processing routes and magnesium-based composites reported in the literature $^{20,23-25,32-40)}$ are summarized in Fig. 8 in the relationship between strength and elongation-to-failure. All materials processed in the present study exhibited a similar yield strength of $\sim 240 \mathrm{MPa}$, which is much higher than the cast AZ91. It is clear that the higher strength obtained in the present materials results from the small grain sizes of $\sim 5 \mu \mathrm{m}$. As seen in Fig. 8(a), the chip-extruded materials tend to exhibit higher yield strength than cast-extruded materials (solid curve versus gray curve). This trend has also been observed in AZ31. ${ }^{41}$ ) The origin of higher strength is assumed to be attributed to the dispersion of oxide, as has been pointed out by Chino et al. $^{41)}$

The ultimate tensile strength gradually decreased with increasing fullerene content: the tensile strength of AZ91/ $\mathrm{C}_{60}-1 \%$ and $\mathrm{AZ} 91 / \mathrm{C}_{60}-5 \%$ was smaller by 8 and $21 \mathrm{MPa}$, respectively, compared with $\mathrm{AZ} 91 / \mathrm{C}_{60}-0 \%$.

Moderate elongation values of $11 \%$ were obtained in $\mathrm{AZ} 91 / \mathrm{C}_{60}-0 \%$ and $\mathrm{AZ91} / \mathrm{C}_{60}-1 \%$. The elongation of $\mathrm{AZ91/}$ $\mathrm{C}_{60}-5 \%$ was slightly smaller $\left(e_{\mathrm{f}}=8 \%\right)$. However, the ductility in the present composites is much higher than other composites, except doubly-extruded ZK60/SiC $\left(e_{\mathrm{f}}=\right.$ $10.5 \%){ }^{40)}$ This may result from the low volume fraction of fullerene.
The tensile properties of $\mathrm{AZ} 91 / \mathrm{C}_{60}-1 \%$ agreed well with the relation for chip-extruded AZ91 alloys (solid curve in Fig. 8). However, the properties for AZ91/ $\mathrm{C}_{60}-5 \%$ deviated from the relation because of the lower elongation value.

The fracture surfaces of $A Z 91 / \mathrm{C}_{60}-0 \%$ and $A Z 91 / \mathrm{C}_{60}-1 \%$ are shown in Fig. 9. They were similar for both materials. The fracture surface of $A Z 91 / \mathrm{C}_{60}-5 \%$ was also similar to those of $A Z 91 / C_{60}-0 \%$ and $A Z 91 / C_{60}-1 \%$. The similarity of the fracture surfaces also indicates that the addition of fullerene had little effect on the tensile behavior of the present materials. Cracks were observed in the micrographs with a low magnification (Figs. 9(a) and (c)) for both materials. It appears that both materials fractured at the interfaces of the original machined chips. The fracture surfaces at a distance from the cracks with a high magnification (Figs. 9(b) and (d)) consisted of ductile dimples for both materials, as has been observed in chip-extruded AZ31. ${ }^{42)}$ The existence of a ductile dimple confirms relatively large elongations of $11 \%$ in the $A Z 91 / C_{60}-0 \%$ and $\mathrm{AZ} 91 / \mathrm{C}_{60}-1 \%$.

\subsection{Damping properties}

The variation in strain amplitude with time during free vibration is shown in Fig. 10 for (a) $\mathrm{AZ91} / \mathrm{C}_{60}-0 \%$, (b) $A Z 91 / C_{60}-1 \%$ and (c) $A Z 91 / C_{60}-5 \%$. The vibration frequencies were calculated to be 957,948 and $926 \mathrm{~Hz}$ for $\mathrm{AZ91} / \mathrm{C}_{60}-0 \%, \mathrm{AZ} 91 / \mathrm{C}_{60}-1 \%$ and $\mathrm{AZ} 91 / \mathrm{C}_{60}-5 \%$, respectively. The decrease in frequency, especially in $A Z 91 / \mathrm{C}_{60^{-}}$ 

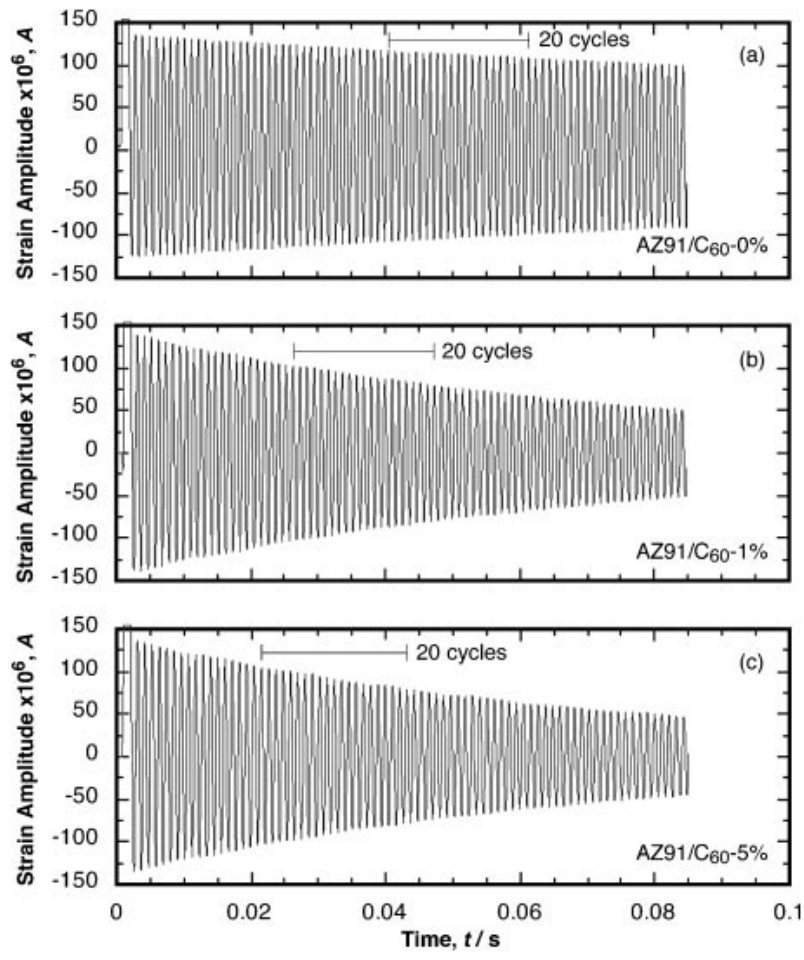

Fig. 10 The variation in strain amplitude with time during free vibration for (a) AZ91/ $\mathrm{C}_{60}-0 \%$, (b) AZ91/ $\mathrm{C}_{60}-1 \%$ and (c) $\mathrm{AZ} 91 / \mathrm{C}_{60}-5 \%$.

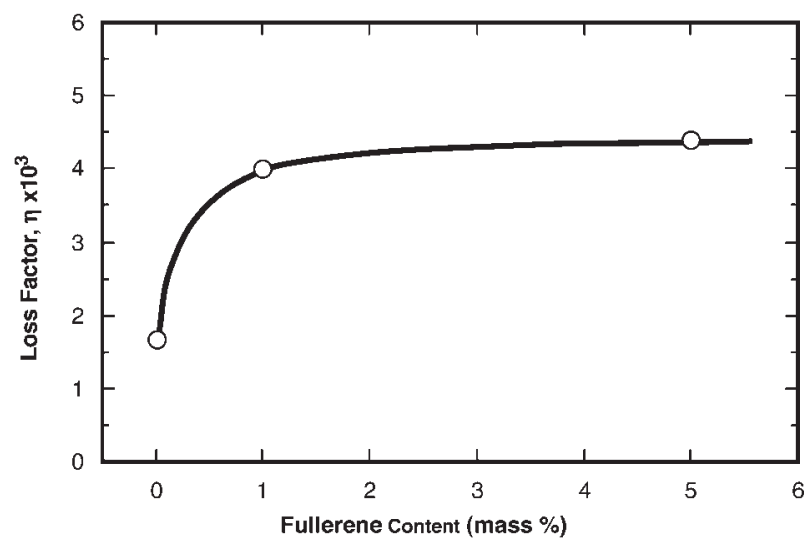

Fig. 11 The variation in loss factor as a function of fullerene content.

$5 \%$, reflects the decrease in modulus, as has been demonstrated in 3.2. The loss factor was calculated at $\varepsilon \sim 10^{-4}$, as indicated in the figure. A steep increase in the loss factor in the composites is evident from Fig. 10. The variation in loss factor as a function of the fullerene content is shown in Fig. 11. The $\mathrm{AZ} 91 / \mathrm{C}_{60}-1 \%$ increased the damping by $\sim 2.5$ times compared with $\mathrm{AZ} 91 / \mathrm{C}_{60}-0 \%$. A small amount of fullerene addition effectively increased the loss factor. Further addition ( 5 mass $\%$ fullerene) had little effect on damping. The effectiveness of the fullerene addition to damping should be related to the unique structure and/or the physical properties of fullerene compared with other carbon materials. The mechanisms responsible for the improved damping of $\mathrm{AZ} 91 / \mathrm{C}_{60}-1 \%$ and $\mathrm{AZ91} / \mathrm{C}_{60}-5 \%$ over $\mathrm{AZ91/}$ $\mathrm{C}_{60}-0 \%$ are discussed in the next section.

\section{Discussion}

The observed loss factor is generally described by a linear superposition of contributions from two or more mechanisms. ${ }^{43)}$ Among the damping mechanisms, the microstructural and thermoelastic effects are thought to be the two primary contributors to damping behavior. ${ }^{44)}$ Though thermoelastic damping is the most important in metals, in which it may comprise most of the damping capacity, ${ }^{45)}$ the contribution is frequency dependent. ${ }^{46)}$ Since the resonant frequencies used in the present study $(f \sim 950 \mathrm{~Hz})$ were much higher than the frequencies where the maximum damping capacity arising from thermoelastic damping would be obtained (e.g., $f \sim 30 \mathrm{~Hz}$ in AZ31 magnesium alloy ${ }^{47)}$ ), the contribution from thermoelastic damping was assumed to be low.

A microstructural effect is associated with the crystal defects. The defects include point defect, dislocations, grain boundaries and microcracks. It is recognized that pure magnesium and some magnesium alloys have a high damping capacity. ${ }^{1-3)}$ The origin is believed to be attributed to the dislocation damping. However, the contribution from dislocation damping increases at $\varepsilon>5 \times 10^{-4}$ in AZ91 alloy, ${ }^{48)}$ which is higher than the condition for the present materials $\left(\varepsilon \sim 10^{-4}\right)$.

Metal-matrix-composites may offer better damping properties than unreinforced alloys owing to the high intrinsic damping capacity of the reinforcements. It is expected that fullerene has high intrinsic damping because of its hollow structure. ${ }^{11)}$ One simple approach that may be utilized to rationalize the observed results that the damping capacity increased with the increasing volume fraction of fullerene is to apply the rule of mixtures. ${ }^{49)}$ Accordingly, the overall damping capacity would be proportional to the individual damping capacities of the matrix and reinforcement multiplied by their respective volume fractions. The relation in Fig. 11 is not depicted as a function of the volume fraction of fullerene. The density of $\mathrm{C}_{60}$ is calculated to be $1.678,{ }^{50}$ ) whereas that of AZ91 is $1.81 .^{20)}$ Therefore, the addition of fullerene powder has little effect on the density of the AZ91/ $\mathrm{C}_{60}$ system. Even if the difference in density is taken into consideration, the linear relation is not obtained for the present composites. The observed non-linear relation indicates that other mechanisms strongly contribute to the overall damping.

Interfacial damping is another possible mechanism. In an interface slip model, interfacial damping is attributed to the friction energy loss between matrix and the additional phase. ${ }^{44)}$ In this model, the overall damping capacity is proportional to the volume fraction of the additional phase. ${ }^{44,51)}$ For the case of weak bonding at the interface, interfacial slip may occur when the magnitude of the shear stress at the interface is sufficient to overcome frictional loads. In the present composites, the formation of the $\mathrm{Al}_{4} \mathrm{C}_{3}$ phase observed in $\mathrm{Al} / \mathrm{C}_{60}$ composites processed by squeeze casting, ${ }^{10)}$ and the $\mathrm{Al}_{4} \mathrm{C}_{3}$ or $\mathrm{Al}-\mathrm{C}-\mathrm{O}$ phases observed in carbon inoculated AZ91 alloy ${ }^{52-54)}$ may not be possible. This is because the processing temperature for the present study was low. Therefore, low interfacial strength is inferred from the absence of an interfacial reaction for the present 
composites. Even though the strain amplitude of the test is low and the temperature is not high, interfacial slip is likely to occur at the interface between the matrix and fullerene phase.

Materials with high strength and stiffness generally have low damping. ${ }^{5)}$ Conversely, a higher damping capacity can often be attained at the expense of stiffness, strength and ductility. Nevertheless, the present composites exhibited a high damping capacity without degrading the stiffness, strength and ductility. For the present composites, interfacial strength is assumed to be low, but the content of fullerene is also low. As a result, the elastic and tensile properties of $A Z 91 / C_{60}-1 \%$ and $A Z 91 / C_{60}-5 \%$ were comparable to those of $\mathrm{AZ} 91 / \mathrm{C}_{60}-0 \%$.

It is known that the damping capacity of cast iron depends on the configuration of graphite. ${ }^{49,55)}$ For example, the damping capacity of spray-deposited 6061Al/Graphite composite is lower than that of its extruded composite counterpart, despite having the same graphite content. ${ }^{49)}$ One of the differences between the two composites is the orientation of the graphite phase: the latter composite assumed a preferred orientation by the extrusion process. This result suggests a dependence of the damping capacity on the orientation of the dispersoids. The BE image and carbon dot map of the present composites clearly showed that the agglomerated fullerene powder was aligned to the extrusion direction. The alignment of fullerene powder may consequently enhance the damping capacity. This contribution possibly brings about a non-linear relation between the loss factor and fullerene content. On the basis of the above considerations, the operative damping mechanisms may be ascribed to the intrinsic damping of fullerene, the interface damping and possibly the alignment of fullerene powder parallel to the extrusion direction. Further research is needed to understand the actual origin of the high damping capacity, and, thus, to optimize the microstructure.

\section{Summary}

The fullerene-dispersed AZ91 magnesium alloy composites were synthesized by means of the extrusion of the mixture of AZ91 machined chips and fullerene powder. The microstructures and mechanical properties, including the elastic moduli, strength, elongation and damping capacity of the processed materials were investigated.

(1) The composites with 1 and 5 mass $\%$ fullerene were successfully produced by the extrusion. There were no voids or cracks in the extruded materials. The extruded materials had equiaxed matrix grains with the size of $\sim 5 \mu \mathrm{m}$, irrespective of the fullerene content. The fullerene powder was agglomerated, but this phase was dispersed uniformly aligned to the extrusion direction.

(2) Both the elastic moduli and tensile properties of the 1 mass $\%$ fullerene-dispersed AZ91 composite were comparable to those of the AZ91 alloy counterpart.

(3) Both the elastic moduli and tensile properties of the 5 mass $\%$ fullerene-dispersed AZ91 composite were slightly lower than those of the AZ91 alloy counterpart.

(4) The damping capacity of the AZ91 alloy composite with only a 1 mass\% fullerene addition was higher by $\sim 2.5$ times compared with the AZ91 alloy counterpart. The dispersion of fullerene to magnesium alloy was verified as a means of efficiently increasing the damping capacity. The operative damping mechanisms may be ascribed to the intrinsic damping of fullerene, the interface damping and possibly the alignment of fullerene powder parallel to the extrusion direction.

\section{Acknowledgement}

The authors are grateful to Mr. T. Niinomi (Frontier Carbon Corp., Japan) for useful discussion.

\section{REFERENCES}

1) K. Sugimoto: Mem. Inst. Sci. Ind. Res., Osaka Univ. 35 (1978) 31-44.

2) K. Sugimoto, K. Matsui, T. Okamoto and K. Kishitake: Trans. JIM 16 (1975) 647-655.

3) K. Sugimoto, K. Niiya, T. Okamoto and K. Kishitake: Trans. JIM 18 (1977) 277-288.

4) T. Mukai and H. Watanabe: Engineering Materials 52 No. 8 (The Nikkan Kogyo Shimbun, Tokyo, 2005) pp. 31-35.

5) C. A. Updike, R. B. Bhagat, M. J. Pechersky and M. F. Amateau: JOM 42 No. 3 (1990) 42-46.

6) J. Gu, X. Zhang and M. Gu: Mater. Trans. 45 (2004) 1743-1747.

7) D. Harada, J. Kaneko, M. Sugamata and M. Kubota: Abstracts of the 108th conference of Japan Institute of Light Metals (2005) pp. 17-18.

8) Z. Trojanová, J. Kiehn, P. Lukác, K. U. Kainer, M. Kulbrok, B. L. Mordike and J. Vincens: Magnesium alloys and their applications, ed. by B. L. Mordike and K. U. Kainer, (Werkstoff-Informationsgesellschaft, Frankfurt, 1998) pp. 241-246.

9) J. Göken and W. Riehemann: Mater. Sci. Eng. A 324 (2002) 127-133.

10) F. A. Khalid, O. Beffort, U. E. Klotz, B. A. Keller, P. Gasser and S. Vaucher: Acta Mater. 51 (2003) 4547-4582.

11) E. V. Barrera, J. Sims, D. L. Callahan, V. Provenzano, J. Milliken and R. L. Holtz: J. Mater. Res. 9 (1994) 2662-2669.

12) E. V. Barrera, J. Sims and D. L. Callahan: J. Mater. Res. 10 (1995) 366371.

13) T. Kuzumaki, K. Miyazawa, H. Ichinose and K. Ito: J. Mater. Res. 13 (1998) 2445-2449.

14) R. Zhong, H. Cong and P. Hou: Carbon 41 (2003) 848-851.

15) T. Noguchi, A. Magario, S. Fukawaza, S. Shimizu, J. Beppu and M. Seki: Mater. Trans. 45 (2004) 602-604.

16) T. Noguchi and J. Beppu: Engineering Materials 52 No. 8 (The Nikkan Kogyo Shimbun, Tokyo, 2005) pp. 36-39.

17) W. A. Scrivens and J. M. Tour: J. Chem. Soc., Chem. Commun. issue 15 (1993) 1207-1209.

18) ASTM C848-88 (1999) Standard test method for Young's modulus, shear modulus, and Poisson's ratio for ceramic whitewares by resonance.

19) I. Nakahara: Applied Elasticity, (Jikko Shuppan, Tokyo, 1978) pp. 117118.

20) ASM Handbook, (ASM Int., Materials Park, Ohio, 1990) pp. 496-497.

21) H. Watanabe, T. Mukai, K. Ishikawa and K. Higashi: Mater. Trans. 43 (2002) 78-80

22) K. Ishikawa, H. Watanabe and T. Mukai: Mater. Lett. 59 (2005) 15111515.

23) L. Li, M. O. Lai, M. Gupta, B. W. Chua and A. Osman: J. Mater. Sci. 35 (2000) 5553-5561

24) A. Martín and J. LLorca: Mater. Sci. Eng. A 201 (1995) 77-87.

25) A. McMinn, R. A. Page and W. Wei: Metall. Trans. 18A (1987) 273281.

26) S. J. Woo, S. H. Lee, E. Kim, K. H. Lee, Y. H. Lee, S. Y. Hwang and I. C. Jeon: Phys. Lett. A 162 (1992) 501-505.

27) Y. Wang, D. Tománek and G. F. Bertsch: Phys. Rev. B 44 (1991) 6562-6565.

28) D. Fioretto, G. Carlotti, G. Socino, S. Modesti, C. Cepek, L. 
Giovannini, O. Donzelli and F. Nizzoli: Phys. Rev. B 52 (1995) R8707-R8710.

29) P. Hess, A. A. Kolomenskii and M. Szabadi: Appl. Surf. Sci. 86 (1995) 591-596.

30) P. Murugavel, C. Narayana, A. Govindaraj, A. K. Sood and C. N. R Rao: Chem. Phys. Lett. 331 (2000) 149-153.

31) S. Berber, E. Osawa and D. Tománek: Phys. Rev. B 70 (2004) $085417-$ 1-085417-6.

32) F. Czerwinski, A. Zielinska-Lipiec, P. J. Pinet and J. Overbeeke: Acta Mater. 49 (2001) 1225-1235.

33) M. Mabuchi, K. Kubota and K. Higashi: J. Jpn. Soc. Powder Powder Metal. 40 (1993) 397-400.

34) M. Mabuchi, K. Kubota and K. Higashi: Mater. Trans., JIM 36 (1995) 1249-1254.

35) C. J. Cáceres, C. J. Davidson, J. R. Griffiths and C. L. Newton: Mater. Sci. Eng. A 325 (2002) 344-355.

36) M. Mabuchi, Y. Chino, H. Iwasaki, T. Aizawa and K. Higashi: Mater Trans. 42 (2001) 1182-1189.

37) J. K. Solberg, J. Tørklep, Ø. Bauger and H. Gjestland: Mater. Sci. Eng A 134 (1991) 1201-1203.

38) H. Iwasaki, K. Yanase, T. Mori, M. Mabuchi and K. Higashi: J. Jpn. Soc. Powder Powder Metal. 43 (1996) 1350-1353.

39) T. Sato, J. Kaneko and M. Sugamata: J. JILM 42 (1992) 345-351.

40) T. Mukai, T. G. Nieh and K. Higashi: Proc. EXPLOMAT '95, ed. by L. E. Murr, K. P. Staudhammer and M. A. Meyers, (Elsevier Science B.V., Amsterdam, 1995) pp. 885-891.
41) Y. Chino, R. Kishihara, K. Shimojima, H. Hosokawa, Y. Yamada, C. Wen, H. Iwasaki and M. Mabuchi: Mater. Trans. 43 (2002) 24372442.

42) H. Watanabe, K. Moriwaki, T. Mukai, K. Ishikawa, M. Kohzu and K. Higashi: J. Mater. Sci. 36 (2001) 5007-5011.

43) W. Duffy, Jr.: J. Appl. Phys. 68 (1990) 5601-5609.

44) E. J. Lavernia, R. J. Perez and J. Zhang: Metall. Mater. Trans. 26A (1995) 2803-2818.

45) R. Lakes: J. Mech. Behav. Mater. 8 (1997) 201-216.

46) C. Zener: Phys. Rev. 53 (1938) 90-99.

47) H. Watanabe, T. Mukai, M. Sugioka and K. Ishikawa: Scripta Mater. 51 (2004) 291-295.

48) J. Göken and W. Riehemann: Mater. Sci. Eng. A 324 (2002) 134-140.

49) R. J. Perez, J. Zhang, M. N. Gungor and E. J. Lavernia: Metall. Trans. 24A (1993) 701-712.

50) W. Krätschmer, L. D. Lamb, K. Fostiropoulos and D. R. Huffman: Nature 347 (1990) 354-358.

51) H.-S. Chu, K.-S. Liu and J.-W. Yeh: J. Mater. Res. 16 (2001) 13721380 .

52) E. Yano, Y. Tamura, T. Motegi and E. Sato: Mater. Trans. 44 (2003) 107-110.

53) M. Qiana and P. Cao: Scripta Mater. 52 (2005) 415-419.

54) D. H. StJohn, MA Qian, M. A. Easton, P. Cao and Z. Hildebrand: Metall. Mater. Trans. 36A (2005) 1669-1679.

55) K. Matsui, A. Matsuo, F. Kizu, M. Takahashi and H. Kanno: J. Japan Inst. Metals 40 (1976) 1062-1068. 